\title{
Risk Factors for Sedation-Related Events During Acute Agitation Management in The Emergency Department
}

Celene Y.L. Yap ${ }^{1,2,3,4}$, David McD. Taylor ${ }^{1,2,5}$, David CM Kong ${ }^{1,4,6}$, Jonathan C Knott ${ }^{1,2,3}$, Simone E Taylor ${ }^{7}$, on behalf of the Sedation for Acute Agitation in Emergency Department Patients: Targeting Adverse Events (SIESTA) Collaborative Study Group ${ }^{\dagger}$

1. Faculty of Medicine, Dentistry and Health Sciences, The University of Melbourne, Parkville, Victoria, Australia

2. Centre for Integrated Critical Care, Department of Medicine and Radiology, Melbourne Medical School, The University of Melbourne, Parkville, Victoria, Australia

3. Emergency Department, The Royal Melbourne Hospital, Parkville, Victoria, Australia

4. Centre for Medicine Use and Safety, Monash University, Parkville, Victoria, Australia

5. Emergency Department, Austin Health, Heidelberg, Victoria, Australia

6. Pharmacy Department, Ballarat Health Services, Ballarat, Victoria, Australia

7. Pharmacy Department, Austin Health, Heidelberg, Victoria, Australia

\section{Authors:}

Dr Celene YL YAP

BPharm, PhD

Research Fellow. Faculty of Medicine, Dentistry and Health Sciences, The University of Melbourne, Parkville, Victoria 3010, Australia.

yen.yap@unimelb.edu.au

Prof David McD TAYLOR (corresponding author)

$\mathrm{MD}, \mathrm{MPH}$

This is the author manuscript accepted for publication and has undergone full peer review but has not been through the copyediting, typesetting, pagination and proofreading process, which may lead to differences between this version and the Version of Record. Please cite this article as doi: 10.1111/ACEM.13826

This article is protected by copyright. All rights reserved 
Director of Emergency Medicine Research. Emergency Department, Austin Health, Studley

Road, Heidelberg, Victoria 3084, Australia

David.Taylor@austin.org.au

Dr David CM KONG
BPharm, PhD

Deputy Director of Pharmacy. Pharmacy Department, Ballarat Health Services, 1 Drummond St N, Ballarat Central, Victoria 3350, Australia.

David.Kong@monash.edu

A/Prof Jonathan C KNOTT

MBBS, PhD

Director of Emergency Research. Emergency Department, The Royal Melbourne Hospital, 300

Grattan Street, Parkville, Victoria 3050, Australia

Jonathan.Knott@mh.org.au

Dr Simone E TAYLOR

BPharm, PharmD

Senior Pharmacist. Pharmacy Department, Austin Health, Studley Road, Heidelberg, Victoria 3084, Australia

Simone.Taylor@austin.org.au

\section{Corresponding Author:}

Professor David Taylor

Emergency Department

Austin Health

PO Box 5555, Heidelberg, Victoria, Australia 3084

David.Taylor@austin.org.au

Phone: +61394964711 
Running Title: Risk factors for sedation-related events during acute agitation

Keywords: antipsychotics, benzodiazepines, agitation, behavioural emergency, adverse events, pharmacological management, sedation

Word count: Abstract 235, Text 2597

\section{Prior Presentations:}

Some study data were presented at the $34^{\text {th }}$ Annual Scientific Meeting of the Australasian College for Emergency Medicine, November 2017, Sydney, Australia.

Funding Sources: SHPA Emergency Medicine Grant 2014 (EME 1402)

Conflicts of interest: All authors report no conflict of interest.

\section{Acknowledgments:}

The authors would like to acknowledge the co-operation and support provided by the staff of the participating emergency departments.

The study was supported by:

- SHPA Emergency Medicine Grant 2014 (EME 1402)

- Emergency Medicine Foundation (EMTR-101R23-2015)

The funding organisations did not have any role in the design or execution of the study, data analysis or interpretation.

\section{$\uparrow$ Additional authors and members of the SIESTA Collaborative Study Group:} Prof Andis GRAUDINS

MBBS (Hons), $\mathrm{PhD}$ 
Director of Monash Health Emergency Medicine and Clinical Toxicology Research Unit. Monash Health, David Street, Dandenong VIC 3175, Australia.

Andis.Graudins@monash.edu

Prof Gerben KEIJZERS

MBBS, PhD

Senior Staff Specialist. Emergency Department, Gold Coast University Hospital, 1 Hospital Boulevard, Southport, QLD 4215, Australia.

Gerben.Keijzers@health.qld.gov.au

Dr Sanjeewa KULAWICKRAMA

MBBS

Emergency Physician. Emergency Department, Gold Coast University Hospital, 1 Hospital Boulevard, Southport, QLD 4215, Australia.

Sanjeewa.Kulawickrama@health.qld.gov.au

Dr Ogilvie THOM

MBBS

Emergency Physician. Emergency Department, Nambour General Hospital, Hospital Road, Nambour

QLD 4560, Australia. ontho25@gmail.com

Dr Luke LAWTON

MBBS (Hons), MPH (Aeromedical Retrieval)

Director of Emergency Medicine, Emergency Department, The Townsville Hospital, IMB 23, PO Box 670, Townsville QLD 4810, Australia.

Luke.Lawton@health.qld.gov.au

Dr Jeremy FURYK

MBBS 
Senior Staff Specialist. Emergency Department, The Townsville Hospital, IMB 23, PO Box 670, Townsville QLD 4810, Australia.

Jeremy.Furyk@health.qld.gov.au

Dr Daniel P FINUCCI

MBBS, MMedSci

Emergency Physician. Emergency Department, Liverpool Hospital, Locked Bag 7103 Liverpool BC, NSW 1871, Australia.

Daniel.Finucci@sswahs.nsw.gov.au

A/Prof Anna HOLDGATE

MBBS, MMed

Director, Emergency Medicine Research Unit, Emergency Department, Liverpool Hospital, Locked Bag 7103 Liverpool BC NSW 1871, Australia.

anna.holdgate@swsahs.nsw.gov.au

Dr Gina WATKINS

MBBS

Senior Emergency Physician. Emergency Department, Sutherland Hospital, Locked Bag 21, Taren Point, NSW 2229, Australia.

Gina.Watkins@sesiahs.health.nsw.gov.au

Dr Peter JORDAN

MBBS

Director of Emergency Medicine. Emergency Department, Northern Health, 185 Cooper Street, Epping VIC 3076, Australia.

Peter.jordan@nh.org.au

Dr Georgina A PHILLIPS

MBBS

Staff Specialist. Emergency Department, St Vincent's Hospital, Victoria Parade, Fitzroy, Victoria 3065, Australia.

This article is protected by copyright. All rights reserved 
drgeorgina@gmail.com

Dr Jonathan KARRO

\section{MBBS}

Staff Specialist. Ėmergency Department, St Vincent's Hospital, Victoria Parade, Fitzroy, Victoria 3065, Australia

jonathan.karro@svhm.org.au

Dr Esther W CHAN

BPharm (Hons), PhD

Associate Professor. Centre for Safe Medication Practice and Research, Department of

Pharmacology and Pharmacy, Li Ka Shing Faculty of Medicine, 2/F Laboratory Block, 21

Sassoon Road, University of Hong Kong, Hong Kong

ewchan@hku.hk

Prof David J CASTLE

MD

Chair of Psychiatry. St Vincent's Hospital and The University of Melbourne, 46 Nicholson Street, Fitzroy, Victoria 3065, Australia

David.CASTLE@sshm.org.au

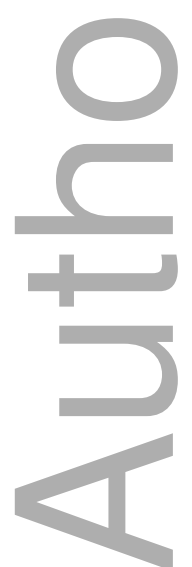


Risk factors for sedation-related events during acute agitation

DR. CELENE YL YAP (Orcid ID : 0000-0001-8359-0605)

3 PROF. DAVID MCDONALD TAYLOR (Orcid ID : 0000-0002-8986-9997)

DR. JONATHAN C KNOTT (Orcid ID : 0000-0003-1503-0440)

Article type :Original Contribution

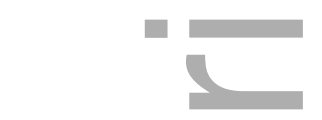

-

ABSTRACT

\section{Objective}

15 To describe the incidence, nature and risk factors for adverse events (AEs) among patients who

16 received parenteral sedation for acute agitation in an emergency department (ED) setting.

\section{Methods}

19 We undertook a prospective observational study and a clinical trial of parenteral sedation for the

20 management of acute agitation. We included agitated adult patients who required parenteral

21 sedation from 2014 to 2017 in twelve Australian EDs, excluding those with incomplete

22 information or aged under 18 years. The primary outcome was the number of patients who

23 experienced at least one AE. Multivariable logistic regression was used to determine factors

24 associated with AEs.

\section{Results}


Risk factors for sedation-related events during acute agitation

904 patients were included in the analyses (62.3\% male; median age 34 years; range 18 to 95 years). Of these, 144 (15.9\%) patients experienced at least one AE. The most common AEs were oxygen desaturation (7.4\%), airway obstruction (3.6\%), bradycardia (1.9\%), hypotension (1.7\%), and prolonged QTc interval (1.3\%). No deaths or serious AEs were reported. The following factors had an increased adjusted odds ratio (OR) for experiencing an AE: age 65 years and older (OR 2.8, 95\% confidence interval [CI] 1.2 to 7.2), more than one type of parenteral sedation administered within 60 minutes (OR 2.1, 95\% CI 1.4 to 3.1), and alcohol intoxication (OR 1.8,

$3495 \%$ CI 1.2 to 2.6$)$.

Conclusions

37 Sedation-related AEs are common, especially respiratory events. Elderly patients, sedation with multiple sedatives within 60 minutes, and alcohol intoxication increased the risk.

\section{INTRODUCTION}

Patients with acute agitation are a common presentation to emergency departments (EDs). A recent study reported that approximately $3 \%$ of ED patients presented with acute agitation, and the majority of them required parenteral sedation. ${ }^{1}$ Care for these patients comes with safety risks for both ED staff and the patients themselves. ${ }^{2}$ As patients presenting with acute agitation can be highly complex with co-morbid medical and substance use issues, there is an increased risk of adverse events (AEs) following parenteral sedation. ${ }^{1,2}$ Nonetheless, few studies have

Sedative medications such as benzodiazepines (e.g. midazolam), typical antipsychotics (e.g. haloperidol, droperidol), and atypical antipsychotics (e.g. olanzapine) are commonly prescribed to manage acute agitation in the ED setting. Previous clinical trials have assessed the efficacy and safety of parenteral sedation for the management of agitation in this ED setting. ${ }^{3-7}$ The need to administer additional study medications or any sedative medications within 60 minutes of the

54 initial dose has been commonly reported. ${ }^{3-7}$ However, it is unknown whether the addition of 55 different sedative medications increases the risk of AEs. 
Risk factors for sedation-related events during acute agitation

57 In addition, the incidence of AEs reported in these trials varies considerably, depending on the 58 pre-specified definitions and the methods for monitoring and documentation. For example, in comparable patient populations, the $\mathrm{AE}$ rate for intramuscular droperidol has been reported to range from $6.0 \%$ to $40.0 \% .^{5,7}$ As there is lack of uniformity in reporting AEs in these trials, it is difficult to compare the AE rates directly. Importantly, none of these efficacy focused trials have sufficient statistical power to identify factors associated specifically with AEs among the patients.

Whilst previous research has demonstrated that intoxication with illicit substances or alcohol are associated with the majority of acute agitation presentations, ${ }^{1-3,5,7}$ the impact of these ingested substances on the occurrence of sedation-related AEs remains understudied. There is limited evidence regarding other factors that may predispose a patient who has received parenteral sedation for acute agitation to AEs. Further investigation into which patient characteristics and treatment-specific variables are associated with the occurrence of AEs may improve patient safety and prevent serious complications in managing acute agitation in EDs.

This study aimed to describe the incidence and nature of AEs among patients who received parenteral sedation for acute agitation in the ED, and to identify risk factors associated with AEs 75 in this patient population.

\section{METHODS}

\section{Study Design and Setting}

79 We analyzed data from a randomized controlled trial (RCT) of parenteral sedation for the 80 management of acute agitation and a prospective observational study of patients in 12 Australian

81 EDs. $^{3,8}$ The annual patient census of these EDs ranged from 50,000 to 100,000 patients. Each

82 ED is supported by 24-hour co-located psychiatric services. Ethics approval for both studies 83 were obtained from the individual governance offices and human research ethics committees. ${ }^{3,8}$ The RCT compared intravenous (IV) midazolam-droperidol combination, IV droperidol alone 86 and IV olanzapine alone for the management of undifferentiated acute agitation in two EDs in 87 Melbourne, Australia. Patients were enrolled between October 2014 and August 2015, inclusive. 
Risk factors for sedation-related events during acute agitation

These two EDs did not participate in the observational study to avoid overlapping between the samples. The observational study was undertaken in the EDs of ten other public, tertiary-referral hospitals across three Australian states (Victoria, Queensland, and New South Wales) between

91 March 2015 and April 2017, inclusive. The observational study was designed to complement AE

92 data obtained from the RCT, in order to increase the sample size for multivariable risk factor

93 analysis.

95 Selection of Participants

96 Patients aged 18 years or older who required parenteral sedation for undifferentiated acute

97 agitation in the participating EDs were enrolled. Cases enrolled more than once into the RCT or

98 with incomplete information were excluded from the analyses. In the RCT, three patients were

99 enrolled twice (about 3-4 hours apart) during the same presentation. Only the initial encounter

100 was included in this analysis of the RCT and observational study patients to avoid double

101 counting of the AE incidence and to improve the accuracy of the logistic regression model.

102 Consecutive patient enrollment was undertaken by assigning patients to the next sequential study

103 pack at their site for the RCT, however, convenience sampling was used for the observational

104 study.

105

106

\section{Methods of Measurements}

107 It is the routine clinical practice in the participating EDs to have one-on-one nursing

108 implemented post-sedation to monitor the patient's vital signs, airway patency and level of

109 sedation. Adverse events were recorded immediately after the administration of parenteral

110 sedation and throughout the ED length of stay. Adverse event data and the time of first parenteral

111 sedation administration were prospectively collected by clinical staff using a designated case

112 report form. To ensure data were collected in a consistent way across all sites by different nurses,

113 definitions of both respiratory and hemodynamic AEs were stated on the case report form and all

114 data were reassessed by the site investigators after the ED presentation, by reviewing the medical 115 record and seeking clarification of any details from the clinicians who cared for the patient in the 116 ED. 
Risk factors for sedation-related events during acute agitation

118 Both studies used the same definitions for the following AEs: respiratory AEs (i.e.

119 hypoventilation [respiratory rate $<10$ breaths/min], oxygen desaturation [oxygen saturation

$120<90 \% \mathrm{mmHg}$ ], partial or complete airway obstruction); cardiovascular AEs (i.e. prolonged QTc

121 [corrected QT > 500ms], tachycardia [heart rate > 100 beats per minute], bradycardia [heart rate

$122<60$ beats per minute]); and other AEs (i.e. extrapyramidal side effects [EPSE], vomiting,

123 anticholinergic side effects [e.g. urinary retention, dry mouth], falls and anaphylaxis). Clinical

124 events such as oxygen desaturation, airway obstruction, hypotension and borderline prolonged

125 QTc occur during the sedation will only able to be detected by nursing staff providing bedside

126 routine care. If other AEs occurred following the sedation (e.g. EPSE), they would have been

127 detected by the attending nursing staff or reported by the patient. Patients were only discharged

128 home after any identified AEs were managed and after being medically cleared. Therefore,

129 clinical events observed and documented by staff on the case report form are considered a

130 reliable source of reported events detected in the ED. Causality of each AE was assessed by the

131 site investigators using the World Health Organization definitions. ${ }^{9}$

133 Site investigators are ED physicians responsible for the conduct of the study at the participating

134 sites. Most participating sites have two site investigators and they have contributed their time in-

135 kind for this study. The role and responsibilities of site investigators including study promotion

136 prior to the study commencement (e.g. conduct training sessions for both nurses and doctors in

137 the ED about the inclusion criteria, AE documentation, etc.), data collection (i.e. collecting

138 demographics data from medical records, assessing AEs reported on the case report form), site

139 support (e.g. answering queries from local staff and the coordinating principal investigators), and

140 assist in the preparation of progress reports and the manuscript. They were not blinded to the

141 study aim.

142

143 Site investigators extracted data on patient demographics and treatment from medical records.

144 Variables extracted retrospectively included gender, age, triage date and time, medication history

145 (i.e. regular psychotropic medications and medications given by paramedics), first dose of

146 parenteral sedation regimen, further parenteral sedation prescribed in the ED within 60 minutes

147 of the first dose, need for mechanical restraint, illicit drugs and alcohol use immediately prior to

148 presentation, final diagnosis and disposition.

This article is protected by copyright. All rights reserved 
Risk factors for sedation-related events during acute agitation

\section{Data Analysis}

151 Sample size calculations were determined a priori for both the $\mathrm{RCT}^{3}$ and the observational

152 study. ${ }^{8}$ For the observational study, our initial sample size was calculated to be at least 1944

153 patients in order to be $95 \%$ certain that the AE rate would range between $11 \%$ and $14 \%$ (level of

154 significance 0.05). However, after recruiting 547 patients, the incidence of AE observed was

$15513.5 \%$ (74/547; [95\% CI 10.9-16.7]), within the expected range. Whilst higher sample numbers

156 will lead to smaller confidence intervals and may increase the chance of detecting rare AEs, we

157 believe the current sample size which afforded 13.5\% AEs appears to have captured the most

158 common types of $\mathrm{AE}$ related to the parenteral sedation in this setting.

160 Patient characteristics, treatment received, incidence and nature of AEs were analyzed

161 descriptively and are reported as frequencies and percentages. For AE data, we calculated

162 differences in proportions with associated 95\% confidence intervals (CI) for patients who

163 received single or multiple types of parenteral sedation within 60 minutes, and for agitation with

164 or without alcohol intoxication.

Adjusted odds ratios (ORs) and 95\% CIs were determined using multiple logistic regression. The

167 independent variables were selected according to clinical plausibility. All variables were entered

168 simultaneously into the model to determine the OR for any AE. As previous work has reported

169 high rates of respiratory AEs post sedation, ${ }^{1,3,6,7}$ we created a second model using the same set

170 of independent variables to determine the OR for any respiratory AE (oxygen desaturation,

171 airway obstruction, or hypoventilation). The independent variables selected for both models

172 included age, gender, regular psychotropic medications, alcohol intoxication, drug intoxication,

173 need for mechanical restraint, sedatives were administered prior to parenteral sedation, and

174 whether multiple types of parenteral sedation were administered within 60 minutes. All variables

175 included in the model are categorical and the outcomes are dichotomous (i.e. yes vs no), hence

176 the assumptions related to extreme values, influential values, and assumption of linearity are not

177 applicable for this model. Collinearity diagnostics were conducted, all variables have tolerance

178 values more than 0.1 , which indicated low intercorrelations among the independent variables

179 included in the logistic regression model. Model fit was assessed for each model with the 
Risk factors for sedation-related events during acute agitation

180

Hosmer-Lemeshow fit statistic. All analyses were performed using IBM SPSS Statistics Version 25 (Armonk. NY: IBM Corp.) and the level of significance was 0.05 .

\section{RESULTS}

\section{Characteristics of study subjects}

Of the 925 cases ( 361 from the RCT and 564 from the observational study) entered into the study database, 21 cases were excluded (one aged less than 18 years, three repeated enrolment, and seventeen incomplete information). The remaining 904 cases (357 from the RCT and 547 from the observational study) had complete data and were included in these analyses.

10

Patient characteristics, type of parenteral sedation administered, and disposition are reported in Table 1. The median age was 34 years (range 18 to 95). Among the 388 (42.9\%) patients identified to have ingested alcohol prior to the ED presentation, approximately one half (46\%) had blood alcohol levels documented. The mean (SD) alcohol level among these patients was $0.21(0.10) \mathrm{g} / \mathrm{dL}$.

\section{Main Results}

Adverse events following parenteral sedation were observed in 144 (15.9\%) patients (Table 2). Respiratory AEs including oxygen desaturation, airway obstruction and hypoventilation were observed in $11.3 \%$ of patients. All patients who experienced a respiratory AE were managed with the administration of oxygen, airway positioning, or bag-mask ventilation. No patient required endotracheal intubation. Cardiovascular AEs including hypotension, QTc prolongation and bradycardia were observed in $4.8 \%$ of patients. However, significantly more patients receiving only olanzapine experienced at least one cardiovascular AEs ( $8.5 \%$ vs $4.2 \%, \mathrm{p}=0.04$ ). Bradycardia was the most commonly reported cardiovascular AE $(17 / 43,40 \%)$, and more than one-third (35\%) of these patients were managed with olanzapine alone. All reported AEs were transient and resolved without adverse clinical outcomes. No deaths were reported.

We found no significant differences in ED length of stay and disposition destination between patients who experienced an $\mathrm{AE}$ and those who did not (Table 1). Although a higher proportion 
Risk factors for sedation-related events during acute agitation

210 of patients who experienced an AE were admitted to the medical ward, all patients were admitted

211 for their underlying medical conditions. No patients were admitted to the medical ward

212 secondary to AEs associated with the management of their acute agitation.

214 After adjustment for other variables, multiple types of parenteral sedation administered within 60

215 minutes (OR 2.1,95\% CI 1.4 to 3.1) and alcohol intoxication (OR 1.8, 95\% CI 1.2 to 2.6) were

216 independently associated with the occurrence of any AEs and with any respiratory AEs (Table

217 3).

\section{DISCUSSION}

To our knowledge, this study is the first to investigate the risk of the occurrence of any AEs in patients who received multiple types of parenteral sedation within 60 minutes of the initial parenteral sedation. To date, most studies related to the management of acute agitation have focused on the efficacy and safety of the initial dose of sedative medication. ${ }^{10,11}$ As most of the sedative medications used in the ED setting for acute agitation have elimination half-lives longer

226 than 60 minutes, any additional sedative medications administered within 60 minutes would

227 likely have additive sedative and respiratory or hemodynamic depression effects. ${ }^{10}$ Hence, in

228 comparison to patients who received only one type of parenteral sedation, agitated patients who

229 received more than one type of parenteral sedation within 60 minutes are at higher risk of

230 experiencing sedation-related AEs. When a different type of parenteral sedation is required to

231 manage an episode of agitation, experienced staff and resuscitation equipment should be

232 immediately available for prompt management of any sedation-related AEs.

234 Adverse events following parenteral sedation for acute agitation are common. Consistent with

235 previous studies, ${ }^{4-7}$ respiratory-related AEs were the most common complications following 236 parenteral sedation in this study. Although previous reviews highlight the potential for serious 237 sedation-related AEs (e.g. Torsades de Pointes [TdP], respiratory depression), ${ }^{11,12}$ it is important 238 to note that, in this study, no patient experienced more than transient morbidity associated with 239 sedation. Regular clinical monitoring with early detection of AEs, may have avoided life- 
Risk factors for sedation-related events during acute agitation

threatening events such as respiratory arrest. This finding serves to emphasize that all patients must receive close monitoring of their vital signs and be attended by personnel skilled in airway management when parenteral sedation is administered.

Droperidol is widely used in the management of acute agitation due to its effectiveness in treating all subsets of acute agitation, including those resulting from stimulant abuse, ${ }^{13,14}$ alcohol intoxication, ${ }^{15}$ head injury, ${ }^{16}$ mania or psychosis ${ }^{17,18}$ and in both elderly ${ }^{19}$ and paediatric ${ }^{20}$ patients. However, the use of droperidol decreased considerably in the United States of America (USA) after the Food and Drug Administration placed a "black box" warning on its use in $2001 .^{21,22}$ This warning highlighted the potential risk of QT prolongation, TdP and sudden death in patients receiving droperidol at the recommended doses. However, our findings indicate that patients receiving droperidol alone reported the lowest incidence of sedation-related AEs. The finding that no patient developed $\mathrm{TdP}$, is consistent with previous reports that the absolute risk of TdP is low. ${ }^{10,12-16,19,26}$ Our findings, therefore, provide additional data to support the safety profile of droperidol for sedation of agitated patients in the ED.

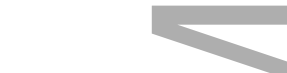

Considering the droperidol shortage in the USA following the black box warning and similar effects and comparable safety profile of droperidol and olanzapine, ${ }^{6,14}$ olanzapine has been the first choice of initial parenteral sedation for acute agitation in some EDs. ${ }^{23,24}$ While previous studies examining patients receiving olanzapine in the ED have reported a low rate of cardiovascular AEs, 6, 23, 25, 26 we found that when compared with patients receiving other parenteral sedation regimens, cardiovascular AEs were more commonly experienced by patients receiving only olanzapine. Bradycardia occurred more frequently than hypotension and QTc prolongation. However, all cardiovascular AEs resolved without sequalae. Despite the difference, our findings add to the published literature supporting the safe use of parenteral olanzapine in ED patients.

Alcohol intoxication is a known risk factor for sedation-related AEs. ${ }^{27,} 28$ Consistent with previous studies, reduction in oxygen saturation was the main respiratory complication in this 
Risk factors for sedation-related events during acute agitation

269 subgroup of patients. ${ }^{24,29}$ One previous study identified that parenteral sedation was associated

270 with increased odds for use of critical care resources by patients with alcohol intoxication and

271 acute agitation presenting to the ED. ${ }^{30}$ Given alcohol has additive effects with other central

272 nervous system depressant medications, regardless of the type of parenteral sedation

273 administered, a high level of vigilance should be maintained following administration of

274 parenteral sedation to patients with alcohol intoxication.

276 Although being elderly, especially aged 65 years and above, is associated with increased odds of

277 experiencing a sedation-related AE when compared with those aged 30 years or less, the

278 proportion of patients sedated for acute agitation in this older age group was relatively small. In

279 this study, it is difficult to distinguish whether the increased risk of harm is due to underlying

280 medical co-morbidities, or other unidentified factors not present in younger patients. Future

281 research with a larger sample size is required to provide a more precise evaluation of this

282 relationship.

283

284

285

This study has several limitations. It was an analysis of data from a RCT and an observational study, which may introduce selection bias. However, as both studies involved adult patients with severe acute agitation that required parenteral sedation, the risk of selection bias is likely to be low. Furthermore, because the occurrence of AEs was monitored and documented in a similar method for both studies, the differences in the study design are unlikely to change the findings.

291 Theoretically, the risk of sedation-related events can be dose-dependent or medication-specific.

292 However, statistical comparisons of AEs associated with different dosage regimens for each

293 sedative medication were not performed, as the statistical power was low when comparing across

294 subgroups. Similarly, we were unable to examine the association between AEs and route of

295 sedative administration (i.e. intravascular vs intramuscular) as some patients received both

296 intravascular and intramuscular sedation within 60 minutes of the initial parenteral sedation. 
Risk factors for sedation-related events during acute agitation

298

299

300

301

302

303

304

305

306

307

308

309

310

311

312

313

314

315

316

317

318

319

320

321

322

323

324

325

This study is also limited by the small numbers of intoxicated patients with a documented blood alcohol level. Final diagnosis of alcohol and illicit drug intoxication was decided by the treating clinician based on historical information, clinical presentation, and/or blood alcohol level.

Specific diagnosis tests were only done where required as part of routine clinical care, therefore the prevalence of alcohol and illicit drug intoxication may be an underestimate. Although alcohol intake appears to be associated with decreasing oxygen saturations, our study was not powered to determine the association between blood alcohol level and the occurrence of AEs. It is also possible that lack of documentation may have led to non-identification of some intoxicated patients. Hence, we may have underestimated the true risk of alcohol intoxication.

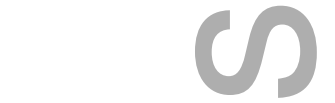

Pre-treatment electrocardiograms (ECGs) are not routinely obtained in the ED for patients with severe agitation, so it is not known whether the QTc prolongations were pre-existing conditions or medication-induced. The low incidence of QTc prolongation in this analysis, and the finding that no patient developed TdP, is consistent with previous reports that the absolute risk of TdP related to parenteral sedation in this group of patients is small. ${ }^{6,31}$ However, firm conclusions cannot be made because the study was not powered to compare QTc intervals, and not all patients had an ECG performed.

\section{CONCLUSIONS}

In summary, patients presenting with acute agitation, especially those aged 65 years and older, intoxicated with alcohol or managed with multiple types of parenteral sedation, carry increased risk of sedation-related AEs. Decades of research has shown that antipsychotics and benzodiazepines, alone or in combination, are effective for use in the management of acute agitation. Although all medications currently used for sedation carry a risk of AEs, our findings suggest that the majority of the AEs can be managed with relatively minor interventions. Hence, an emphasis should be placed on close physiologic monitoring to ensure early detection and management of these AEs, regardless of the type of parenteral sedation administered to manage the acute agitation. 
Risk factors for sedation-related events during acute agitation

\section{REFERENCES}

1. Miner JR, Klein LR, Cole JB, Driver BE, Moore JC, Ho JD. The Characteristics and Prevalence of Agitation in an Urban County Emergency Department. Ann Emerg Med 2018;72:361-70.

2. Oliver Matthew, Adonopulos Aaron A, Haber Paul S, et al. Impact of acutely behavioural disturbed patients in the emergency department: A prospective observational study. Emerg Med Australas 2018; https://doi.org/10.1111/1742-6723.13173.

3. Taylor DM, Yap CYL, Knott JC, et al. Midazolam-Droperidol, Droperidol, or Olanzapine for Acute Agitation: A Randomized Clinical Trial. Ann Emerg Med 2017;69:318-26.e1.

4. Knott JC, Taylor DM, Castle DJ. Randomized Clinical Trial Comparing Intravenous Midazolam and Droperidol for Sedation of the Acutely Agitated Patient in the Emergeney Department. Ann Emerg Med 2006;47:61-7.

5. Isbister GK, Calver LA, Page CB, Stokes B, Bryant JL, Downes MA. Randomized Controlled Trial of Intramuscular Droperidol Versus Midazolam for Violence and Acute Behavioral Disturbance: The DORM Study. Ann Emerg Med 2010;56:392-401.

6. Chan EW, Taylor DM, Knott JC, Phillips GA, Castle DJ, Kong DC. Intravenous droperidol or olanzapine as an adjunct to midazolam for the acutely agitated patient: a multicenter, randomized, double-blind, placebo-controlled clinical trial. Ann Emerg Med 2013;61:72-81.

7. Martel M, Sterzinger A, Miner J, Clinton J, Biros M. Management of acute undifferentiated agitation in the emergency department: a randomized double-blind trial of droperidol, ziprasidone, and midazolam. Acad Emerg Med 2005;12:1167-72.

8. Yap CYL, Taylor DM, Kong DC, et al. Management of Behavioural Emergencies: A Prospective Observational Study in Australian Emergency Departments. JPPR 2018;In press.

9. Edwards I, Aronson J. Adverse drug reactions: definitions, diagnosis, and management. Lancet 2000;356:1255 - 9.

10. Battaglia J. Pharmacological management of acute agitation. Drugs 2005;65:1207-22.

11. Zun LS. Evidence-Based Review Of Pharmacotherapy For Acute Agitation. Part 2: Safety. J Emerg Med 2018;54:522-32. 
Risk factors for sedation-related events during acute agitation

12. Pacciardi B, Mauri M, Cargioli C, et al. Issues in the management of acute agitation: how much current guidelines consider safety? Frontiers in psychiatry 2013;4:https://doi.org/10.3389/fpsyt.2013.00026.

13. Richards J, Derlet R, Duncan D. Methamphetamine toxicity: treatment with a benzodiazepine versus a butyrophenone. Eur J Emerg Med 1997;4:130-5.

14. Yap CYL, Taylor DM, Knott JC, et al. Intravenous midazolam-droperidol combination, droperidol or olanzapine monotherapy for methamphetamine-related acute agitation: subgroup analysis of a randomized controlled trial. Addiction 2017;112:1262-9.

15. Thomas Jr H, Schwartz E, Petrilli R. Droperidol versus haloperidol for chemical restraint of agitated and combative patients. Ann Emerg Med 1992;21:407-13.

16. Stanislav SW, Childs A. Evaluating the usage of droperidol in acutely agitated persons with brain injury. Brain Inj 2000;14:261-5.

17. Chambers RA, Druss BG. Droperidol: efficacy and side effects in psychiatric emergencies. J Clin Psychiatry 1999;60:664-7.

18. Cure S, Carpenter S. Droperidol for acute psychosis. Cochrane Database Syst Rev 2001:CD002830.

19. Calver L, Isbister GK. Parenteral sedation of elderly patients with acute behavioral disturbance in the ED. Am J Emerg Med 2013;31:970-3.

20. Szwak K, Sacchetti A. Droperidol use in pediatric emergency department patients. Pediatr Emerg Care 2010;26:248-50.

21. Richards JR, Schneir AB. Droperidol in the emergency department: is it safe? J Emerg Med 2003;24:441-7.

22. Richards JR, Weiss SJ, Bretz SW, Schneir AB, Rinetti D, Derlet RW. The effects of the FDA warning on the use of droperidol by u.s. Emergency physicians. Cal J Emerg Med 2003;4:3-9.

23. Martel ML, Klein LR, Rivard RL, Cole JB. A Large Retrospective Cohort of Patients Receiving Intravenous Olanzapine in the Emergency Department. Acad Emerg Med 2016;23:29-35.

24. Wilson MP, Chen N, Vilke GM, Castillo EM, MacDonald KS, Minassian A. Olanzapine in ED patients: differential effects on oxygenation in patients with alcohol intoxication. $\mathbf{J}$ Emerg Med 2012;30:1196-201. 
Risk factors for sedation-related events during acute agitation

25. Cole JB, Moore JC, Dolan BJ, et al. A Prospective Observational Study of Patients Receiving Intravenous and Intramuscular Olanzapine in the Emergency Department. Ann Emerg Med 2017;69:327-36.e2.

26. Meehan KM, Wang H, David SR, et al. Comparison of rapidly acting intramuscular olanzapine, lorazepam, and placebo: a double-blind, randomized study in acutely agitated patients with dementia. Neuropsychopharmacology 2002;26:494-504.

27. Carole W, Sherry L, Taasan VC, Block AJ, Boysen PG, Wynne JW. Alcohol increases sleep apnea and oxygen desaturation in asymptomatic men. The American Journal of Medicine 1981;71:240-5.

28. Vonghia L, Leggio L, Ferrulli A, Bertini M, Gasbarrini G, Addolorato G. Acute alcohol intoxication. Eur J Intern Med 2008;19:561-7.

29. Wilson MP, MacDonald K, Vilke GM, Ronquillo L, Feifel D. Intramuscular Ziprasidone: Influence of Alcohol and Benzodiazepines on Vital Signs in the Emergency Setting. J Emerg Med 2013;45:901-8.

30. Klein LR, Cole JB, Driver BE, Battista C, Jelinek R, Martel ML. Unsuspected Critical Illness Among Emergency Department Patients Presenting for Acute Alcohol Intoxication. Ann Emerg Med 2018;71:279-88.

31. Calver L, Isbister GK. High dose droperidol and QT prolongation: analysis of continuous 12-lead recordings. Br J Clin Pharmacol 2014;77:880-6.

Table 1. Characteristics of the study population.

\begin{tabular}{lccc}
\hline Characteristics & $\begin{array}{c}\text { Total } \\
\text { Population } \\
(\mathbf{N = 9 0 4 )}\end{array}$ & $\begin{array}{c}\text { Any AE } \\
(\mathbf{n = 1 4 4})\end{array}$ & $\begin{array}{c}\text { Respiratory AE } \\
(\mathbf{n = 9 2})\end{array}$ \\
\hline Age, years, n (\%) & 321 & $47(14.6)$ & $32(10.0)$ \\
$18-30$ & 549 & $89(16.2)$ & $57(10.4)$ \\
$31-64$ & 34 & $8(23.5)$ & $3(8.8)$ \\
$\geq 65$ & 563 & $100(17.8)$ & $69(12.3)$ \\
Male, $\mathbf{n}$ (\%) & & & \\
ICD-10 category, $\mathbf{n}(\%)$ & 347 & $49(14.1)$ & $26(7.5)$ \\
Mental illness & 472 & $80(17.0)$ & $56(11.9)$ \\
Intoxication (drugs and/or alcohol) & & &
\end{tabular}


Risk factors for sedation-related events during acute agitation

\begin{tabular}{|c|c|c|c|}
\hline Characteristics & $\begin{array}{c}\text { Total } \\
\text { Population } \\
(\mathrm{N}=904)\end{array}$ & $\begin{array}{l}\text { Any AE } \\
(n=144)\end{array}$ & $\begin{array}{c}\text { Respiratory AE } \\
(\mathbf{n}=92)\end{array}$ \\
\hline \multicolumn{4}{|l|}{ Regular psychotropic medications, $\mathbf{n}(\%)^{\mathrm{a}}$} \\
\hline Benzodiazepines & 91 & $13(14.3)$ & $6(6.6)$ \\
\hline SSRI or SNRI & 84 & $17(20.2)$ & $10(11.9)$ \\
\hline Atypical antipsychotics & 153 & $22(14.4)$ & $13(8.5)$ \\
\hline Typical antipsychotics & 33 & $2(6.1)$ & $1(3.0)$ \\
\hline Prescription opioids ${ }^{b}$ & 70 & $5(7.1)$ & $2(2.9)$ \\
\hline Alcohol intoxication, n (\%) & 388 & $77(19.9)$ & $55(14.2)$ \\
\hline Illicit drug intoxication, $\mathbf{n}(\%)$ & 391 & $61(15.6)$ & $37(9.5)$ \\
\hline \multicolumn{4}{|l|}{$\begin{array}{l}\text { Sedatives administered prior the initial } \\
\text { parenteral sedation, } n(\%)\end{array}$} \\
\hline Intramuscular midazolam $^{c}$ & 32 & $9(25.7)$ & $6(18.8)$ \\
\hline Oral diazepam & 43 & $7(16.3)$ & $5(11.6)$ \\
\hline Oral olanzapine & 25 & $2(8.0)$ & $1(4.0)$ \\
\hline Oral risperidone & 4 & $2(50.0)$ & $0(0.0)$ \\
\hline Oral diazepam and olanzapine & 26 & $4(15.4)$ & $3(11.5)$ \\
\hline \multicolumn{4}{|l|}{$\begin{array}{l}\text { Type of parenteral sedation administered } \\
\text { within } 60 \text { minutes, } n(\%)\end{array}$} \\
\hline \multicolumn{4}{|l|}{ Single sedative } \\
\hline Droperidol & 473 & $54(11.4)$ & $32(6.8)$ \\
\hline Olanzapine & 118 & $22(18.6)$ & $10(8.5)$ \\
\hline Midazolam & 48 & $6(12.5)$ & $5(10.4)$ \\
\hline Others $^{\mathrm{d}}$ & 10 & $2(20.0)$ & $1(10.0)$ \\
\hline \multicolumn{4}{|l|}{ Multiple sedatives } \\
\hline Midazolam + antipsychotics ${ }^{\mathrm{e}}$ & 217 & $54(24.9)$ & $41(18.9)$ \\
\hline $\begin{array}{l}\text { Typical antipsychotics + atypical } \\
\text { antipsychotics }\end{array}$ & 19 & $3(15.8)$ & $0(0.0)$ \\
\hline Ketamine + other sedatives ${ }^{\mathrm{g}}$ & 10 & $3(30.0)$ & $3(30.0)$ \\
\hline Other combinations ${ }^{h}$ & 9 & $0(0.0)$ & $0(0.0)$ \\
\hline ED length of stay, hours, median (IQR) & 10.1 & 9.2 & 8.9 \\
\hline
\end{tabular}

This article is protected by copyright. All rights reserved 
Risk factors for sedation-related events during acute agitation

\begin{tabular}{lccc}
\hline Characteristics & $\begin{array}{c}\text { Total } \\
\text { Population } \\
(\mathbf{N = 9 0 4 )}\end{array}$ & $\begin{array}{c}\text { Any AE } \\
(\mathbf{n = 1 4 4})\end{array}$ & $\begin{array}{c}\text { Respiratory AE } \\
(\mathbf{n = 9 2})\end{array}$ \\
\hline & $(6.0$ to 15.2) & $(5.4$ to 14.3) & $(5.6$ to 12.3) \\
Disposition, $\mathbf{n}(\boldsymbol{\%})$ & & & $52(11.0)$ \\
Home & 474 & $71(15.0)$ & $22(7.8)$ \\
Psychiatric ward & 282 & $40(14.2)$ & $8(10.1)$ \\
Medical ward & 79 & $17(21.5)$ & $7(15.9)$ \\
ED observational ward & 44 & $12(27.3)$ & $3(12.0)$ \\
Oher facilities & 25 & $4(16.0)$ &
\end{tabular}

ICD-10=International Classification of Diseases; IQR= Interquartile range SSRI=selective serotonin reuptake inhibitor; SNRI=serotonin noradrenalin-reuptake inhibitor

${ }^{a}$ Patients could have been administered more than one type of regular psychotropic medications prior to the presentation.

${ }^{\mathrm{b}}$ Prescription opioids included buprenorphine, codeine, fentanyl, methadone, morphine, oxycodone, tramadol

${ }^{\mathrm{c}}$ Intramuscular midazolam administered by paramedics before arriving emergency departments.

${ }^{\mathrm{d}}$ Other sedative medications included haloperidol, diazepam, lorazepam, and propofol.

${ }^{\mathrm{e}}$ Antipsychotics that had been administered within an hour before or after sedation with midazolam included droperidol, olanzapine, and haloperidol.

${ }^{\mathrm{f}}$ Combination of antipsychotics included droperidol-olanzapine, and haloperidol-risperidone.

g Sedatives that had been administered within an hour before or after sedation with ketamine included midazolam, droperidol, clonazepam, and morphine.

${ }^{\mathrm{h}}$ Other combinations of sedatives included droperidol-diazepam, droperidol-clonazepam, and droperidol-lorazepam.

${ }^{\mathrm{i}}$ Other facilities included correctional facilities, assisted accommodation and police

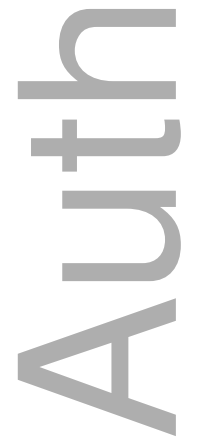


Risk factors for sedation-related events during acute agitation

Table 2. Frequency and nature of sedation-related adverse events.

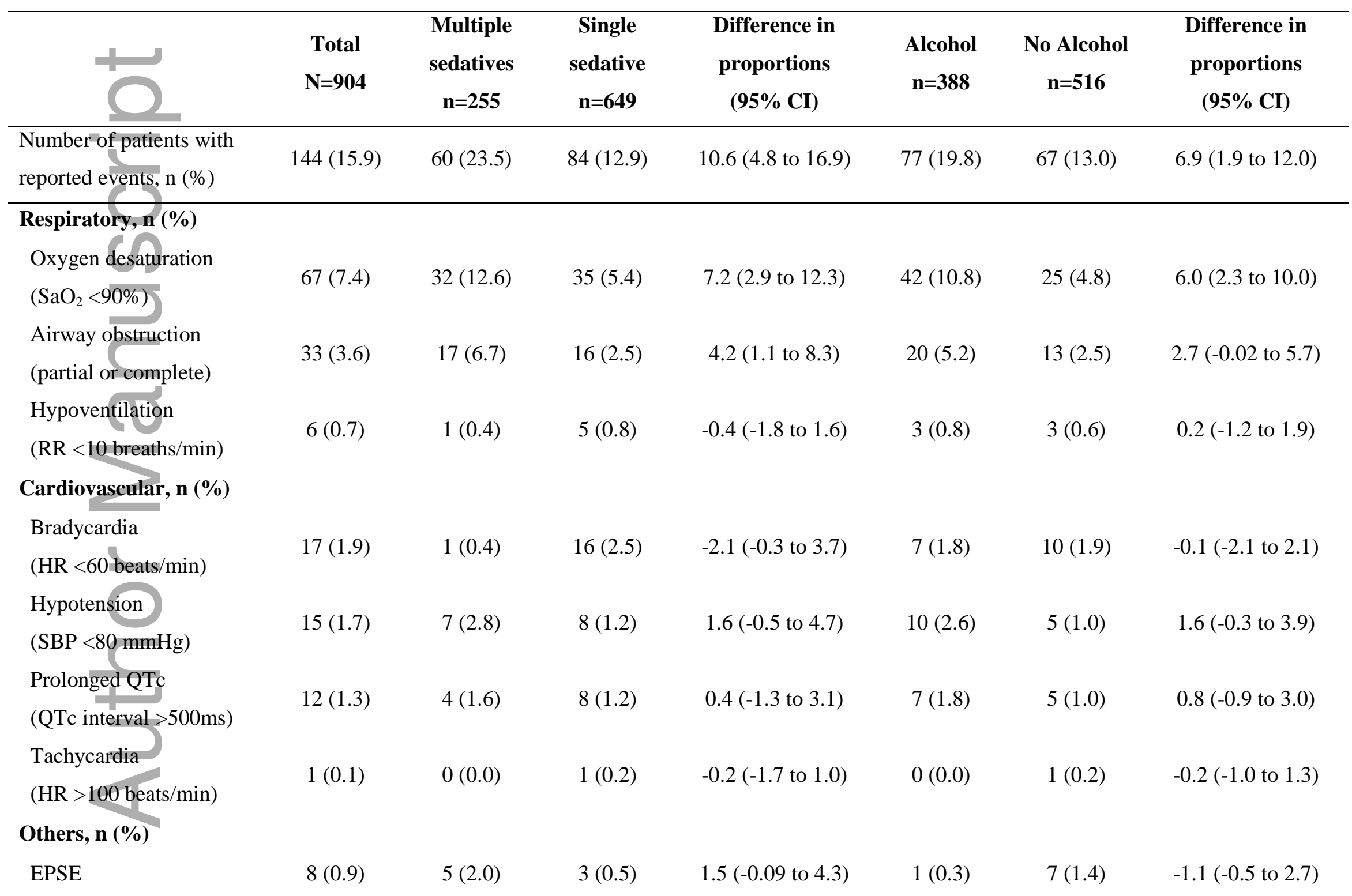

This article is protected by copyright. All rights reserved 
Risk factors for sedation-related events during acute agitation

\begin{tabular}{lccccccc}
\hline & $\begin{array}{c}\text { Total } \\
\mathbf{N = 9 0 4}\end{array}$ & $\begin{array}{c}\text { Multiple } \\
\text { sedatives } \\
\mathbf{n = 2 5 5}\end{array}$ & $\begin{array}{c}\text { Single } \\
\text { sedative } \\
\mathbf{n = 6 4 9}\end{array}$ & $\begin{array}{c}\text { Difference in } \\
\text { proportions } \\
(\mathbf{9 5 \%} \mathbf{C I})\end{array}$ & $\begin{array}{c}\text { Alcohol } \\
\mathbf{n = 3 8 8}\end{array}$ & $\begin{array}{c}\text { No Alcohol } \\
\mathbf{n = 5 1 6}\end{array}$ & $\begin{array}{c}\text { Difference in } \\
\text { proportions } \\
(\mathbf{9 5 \%} \mathbf{C I})\end{array}$ \\
\hline Vomiting & $2(0.2)$ & $1(0.4)$ & $1(0.2)$ & $0.2(-0.7$ to 2.4$)$ & $1(0.3)$ & $1(0.2)$ & $0.1(-0.1$ to 1.5$)$ \\
Urinary retention & $2(0.2)$ & $1(0.4)$ & $1(0.2)$ & $0.2(-0.7$ to 2.4$)$ & $0(0.0)$ & $2(0.4)$ & $-0.4(-0.9$ to 1.5$)$ \\
Dry mouth & $1(0.1)$ & $0(0.0)$ & $1(0.2)$ & $-0.2(-1.7$ to 1.0$)$ & $0(0.0)$ & $1(0.2)$ & $-0.2(-1.0$ to 1.3$)$ \\
Fall & $1(0.1)$ & $1(0.4)$ & $0(0.0)$ & $0.4(-0.4$ to 2.5$)$ & $1(0.3)$ & $0(0.0)$ & $0.3(-0.7$ to 1.7$)$ \\
Anaphylaxis & $1(0.1)$ & $0(0.0)$ & $1(0.2)$ & $-0.2(-1.7$ to 1.0$)$ & $0(0.0)$ & $1(0.2)$ & $-0.2(-1.0$ to 1.3$)$ \\
Total cases of AEs, $\mathbf{n}(\boldsymbol{\%})$ & $166(18.3)$ & $70(27.5)$ & $96(14.8)$ & $12.7(6.6$ to 19.2$)$ & $92(23.7)$ & $74(14.3)$ & $9.4(4.1$ to 14.8$)$ \\
\hline
\end{tabular}

$\mathrm{AE}=$ adverse event; $\mathrm{EPSE}=$ Extrapyramidal side effects; $\mathrm{HR}=$ heart rate; $\mathrm{QTc}=$ corrected $\mathrm{QT}$ interval; $\mathrm{RR}=$ respiratory rate; $\mathrm{SaO}_{2}=$ oxygen saturation;

$\mathrm{SBP}=$ systolic blood pressure

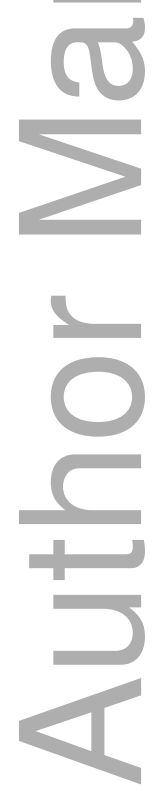

This article is protected by copyright. All rights reserved 
Risk factors for sedation-related events during acute agitation

Table 3. Multivariable logistic regression model for adverse events for total population $(\mathrm{n}=904)$.

\begin{tabular}{|c|c|c|c|c|}
\hline \multirow{2}{*}{ Variables } & \multicolumn{2}{|c|}{ Any AE } & \multicolumn{2}{|c|}{ Respiratory AE } \\
\hline & $\mathbf{O R}^{*}$ & $(95 \% \mathrm{CI})$ & OR* & $(95 \% \mathrm{CI})$ \\
\hline \multicolumn{5}{|l|}{ Age, years } \\
\hline $18-30^{\mathrm{a}}$ & - & - & - & - \\
\hline $31-64 \square$ & 1.2 & $(0.8$ to 1.8$)$ & 1.1 & $(0.7$ to 1.8$)$ \\
\hline$\geq 65$ & 2.8 & $(1.1$ to 7.1$)$ & 1.5 & $(0.4$ to 5.7$)$ \\
\hline Male & 1.4 & $(1.0$ to 2.1$)$ & 2.0 & $(1.2$ to 3.3$)$ \\
\hline Regular psychotropic medications & 0.9 & (0.6 to 1.3$)$ & 0.8 & $(0.5$ to 1.3$)$ \\
\hline Alcohol intoxicated & 1.8 & $(1.2$ to 2.6$)$ & 2.2 & $(1.4$ to 3.5$)$ \\
\hline Illicit drug intoxicated & 1.0 & $(0.7$ to 1.5$)$ & 0.8 & $(0.5$ to 1.3$)$ \\
\hline Need for mechanical restraint & 1.3 & $(0.9$ to 1.9$)$ & 1.6 & (1.0 to 2.6$)$ \\
\hline $\begin{array}{l}\text { Sedatives were administered prior parenteral } \\
\text { sedation }\end{array}$ & 1.3 & $(0.8$ to 2.1$)$ & 1.3 & (0.7 to 2.4$)$ \\
\hline $\begin{array}{l}\text { Multiple types of parenteral sedation were } \\
\text { administered within } 60 \text { minutes }\end{array}$ & 2.1 & $(1.5$ to 3.1$)$ & 2.6 & (1.6 to 4.1$)$ \\
\hline
\end{tabular}

\footnotetext{
*Adjusted odds ratio (OR) generated by the simultaneous entry of covariates in the logistic regression model. The $\mathrm{P}$ value for Hosmer-Lemeshow goodness-of-fit statistics for all AE and respiratory AE is 0.990 and 0.815 , respectively.

${ }^{a}$ Reference group with which other groups are compared.
} 


\section{University Library}

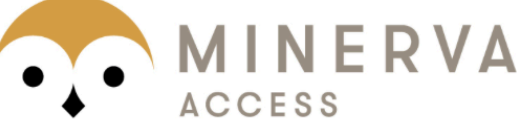

A gateway to Melbourne's research publications

Minerva Access is the Institutional Repository of The University of Melbourne

\section{Author/s:}

Yap, CYL;Taylor, DM;Kong, DCM;Knott, JC;Taylor, SE;Graudins, A;Keijzers, G;Kulawickrama, S;Thom, O;Lawton, L;Furyk, J;Finucci, DP;Holdgate, A;Watkins, G;Jordan, P;Phillips, GA;Karro, J;Chan, EW;Castle, DJ

Title:

Risk Factors for Sedation-related Events During Acute Agitation Management in the Emergency Department

Date:

2019-07-24

Citation:

Yap, C. Y. L., Taylor, D. M., Kong, D. C. M., Knott, J. C., Taylor, S. E., Graudins, A., Keijzers, G., Kulawickrama, S., Thom, O., Lawton, L., Furyk, J., Finucci, D. P., Holdgate, A., Watkins, G., Jordan, P., Phillips, G. A., Karro, J., Chan, E. W. \& Castle, D. J. (2019). Risk Factors for Sedation-related Events During Acute Agitation Management in the Emergency Department. ACADEMIC EMERGENCY MEDICINE, 26 (10), pp.1135-1143. https://doi.org/10.1111/ acem. 13826.

Persistent Link:

http://hdl.handle.net/11343/286201 